\title{
Cutaneous Leishmaniasis in Erbil Governorate: Clinical manifestations and disease course
}

\author{
Dindar Sharif Qurtas*1
}

Received: 25 Dec 2017

\author{
Published: 12 Aug 2018
}

\begin{abstract}
Background: Cutaneous leishmaniasis (CL) is an infectious disease of zoonotic characteristic; its etiological agent is a protozoan of Leishmania species. This infectious agent is transmitted to humans through a secondary vector, which is infected sand-fly. According to WHO report, Iraq is a country where cutaneous leishmaniasis is an emerging disease, especially, its rural areas are labeled to be the source of the infection and endemicity. Course of the disease and treatment is highly defined by the subtype of cutaneous leishmaniasis and its species.

Methods: Data were collected from cutaneous leishmaniasis registry database of Erbil Dermatology Teaching Center in city of Erbil from August 2016 to August 2017. The collected data were descriptively analyzed for the clinical manifestations and the course of disease in the outbreak of this disease in Erbil governorate.

Results: A total of 124 patients were enrolled in this study. Among them, 93 (75\%) were male and $31(25 \%)$ were female. Their age ranged from 2 years to 73 years, with the mean age of $30.7 \pm 11.3$. The majority of the patients were members of army forces. The total number of the lesions was 325. The number of lesions being ulcerated at the time of presentation was $179(55 \%)$ and non-ulcerated lesions 146 (45\%). Time needed for improvement ranged from 1.5 to 4.8 months. Recovery time of cutaneous leishmaniasis lesions from time of onset to the remission ranged from 1.3 to 14.3 months.

Conclusion: The complete recovery time of the CL lesions was longer than what has been mentioned previously in Iraq. Ulceration of the lesions depends on the diameter of the lesions, as increased diameter increases the possibility of the ulceration. The possibility of lesion ulceration increases with an increase in the diameter of the lesions. Considering the observations in different clinical patterns and course of this disease, further studies should be conducted to identify CL species.
\end{abstract}

Keywords: Cutaneous leishmaniasis, Clinical manifestation, Ulceration

Copyright $\odot$ Iran University of Medical Sciences

Cite this article as: Dindar Sh Qurtas. Cutaneous Leishmaniasis in Erbil Governorate: Clinical manifestations and disease course. Med J Islam Repub Iran. 2018 (12 Aug);32:71. https://doi.org/10.14196/mjiri.32.71.

\section{Introduction}

Cutaneous leishmaniasis (CL) is an infectious disease with zoonotic characteristic; its etiological agent is a protozoan of Leishmania species. The infectious agent is transmitted to humans through a secondary vector, which is infected sand-fly (1-3).

In general, the prevalence of leishmaniasis in early $21^{\text {st }}$ century was about 12 million cases. CL annual incidence is about 1.5 million (4).

The disease is endemic in many non-developed countries. Generally, its geographical map of endemicity is divided into 2 areas: the new world leishmaniasis and old world leishmaniasis. The majority of endemic countries

Corresponding author: Dr Dindar Sharif Qurtas, dindar.qurtas@med.hmu.edu.krd, 1. College of Medicine Hawler Medical University, Erbil Dermatology Teaching Center, Erbil, Iraq. are developing or non-developed ones, including Iraq and its neighboring countries (Iran, Turkey, Syria, and Lebanon). In Western countries, the incidence of CL is due to human immunodeficiency virus infection or tourism $(2,3$, 5).

According to WHO report, Iraq is regarded as a country where CL is an emerging disease, especially, rural areas are labeled as source of infection and endemicity $(1,2,4)$.

Primary lesion of CL is ought to be a small papule or papules developed at the site of bite of the infected sandfly. These papules evolve over time to become nodule and, sometimes, their ulcerate ends by scar formation.

$\uparrow$ What is "already known" in this topic:

Cutaneous leishmaniasis could have different course of presentations depending on the species and immune reactivity of the human body.

$\rightarrow$ What this article adds:

Ulceration of the cutaneous leishmaniasis occurs in relation to the diameter of the lesion. Lesions diameter equal or more than $2 \mathrm{~cm}$ are prone to ulceration on healing. 
Lesion of CL may take months to 1 year to resolve. Lesions could be solitary or multiple according to the species of Leishmania. Sometimes, the lesion could be superinfected by bacteria, making the course of the disease more complicated and resistant to treatment $(5,6)$.

Dermatoses could resolve without any treatment, especially, if the number of lesions is limited. Both wet and dry types of lesions are supposed to be determined by the type of species and method of transmission of the disease. In Leishmania major, also called the rural type of cutaneous leishmaniasis, the lesions are dry, small, and multiple. On the contrary, in Leishmania tropica, also called the urban type, the lesions are wet, large, and limited $(2,7)$.

Course of the disease and treatment is highly defined by the type of cutaneous leishmaniasis. Type of the lesions and their liability to become superinfection by bacteria complicates the course of the disease and the response to traditional and standard treatments. Thus, the treatment plan offered by dermatologists is highly affected by the clinical presentations of cutaneous leishmaniasis $(1,5,7)$. The aim of this study was to evaluate the course and manifestation of this newly emerged disease in Erbil Governorate.

\section{Methods}

The study design was retrospective. Data were collected from CL registry database of Erbil Dermatology Teaching Center. Case sheets of 124 new cases from August 2016 to August 2017 were included in this study. Patients were diagnosed and registered for their clinical manifestation at Erbil Dermatology Teaching Center outpatient department. Cases were received by dermatologists, anamnesis taken thoroughly, and clinical examination done. All data were collected during the examination of patients and were registered to the cutaneous leishmaniasis record sheets. Data collected from the patients' records were descriptively analyzed for clinical manifestations and course of the disease in its outbreak in Erbil Governorate.

\section{Statistical analysis}

Data were analyzed descriptively by SPSS software version 22 .

\section{Results}

From 124 patients, 93 (75\%) were male and 31 (25\%) were female. Their age ranged from 2 years to 73 years, with the mean age of $30.7 \pm 11.3$. The majority of the patients were members of army forces (Table 1). Highest incidence of CL was in January and December, 20\% and $24 \%$, respectively (Fig. 1). The total number of CL lesion was 325 , and the mean of lesions for each patient was $2.6 \pm 1.5$, with the average of 2.6 (Table 2). Exposed areas of the body were the most common sites of lesions. Forearm and foot had the largest proportion of the lesions, $20 \%$ and $23 \%$, respectively (Fig. 2). The lesions being ulcerated at the time of presentation were $179(55 \%)$ and non-ulcerated lesions 146 (45\%) (Table 2). At the time of presentation, patients received treatment, which included weekly intralesional sodium stibogluconate (pentostam) for cases having 5 or less lesions, and cases having more

\begin{tabular}{|c|c|c|}
\hline Parameters & No & Percent $\%$ \\
\hline \multicolumn{3}{|l|}{ Sex } \\
\hline Male & 93 & 75 \\
\hline Female & 31 & 25 \\
\hline \multicolumn{3}{|l|}{ Age } \\
\hline up to 14 years & 19 & 15.3 \\
\hline $15-34$ years & 46 & 37.1 \\
\hline $35-54$ years & 53 & 42.7 \\
\hline 55 and More & 6 & 4.8 \\
\hline \multicolumn{3}{|l|}{ Occupation } \\
\hline Child & 14 & 11.3 \\
\hline Student & 16 & 12.9 \\
\hline Business man & 16 & 12.9 \\
\hline Government & 6 & 4.8 \\
\hline \multicolumn{3}{|l|}{ Employment } \\
\hline House wife & 22 & 17.7 \\
\hline Army forces member & 50 & 40.3 \\
\hline
\end{tabular}

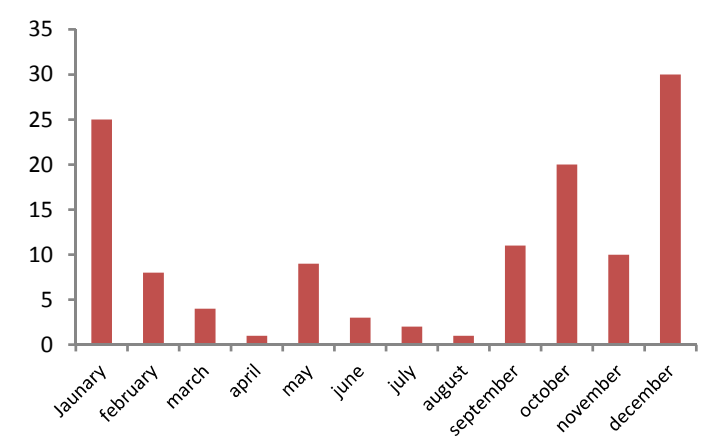

Fig. 1. The incidence of CL lesions over a year

Table 2. Diameter of lesions in relation to the ulceration

\begin{tabular}{cccc}
\hline Diameter of lesions/ cm & Ulcerated & Not Ulcerated & Total \\
\hline $0.1-0.9$ & 1 & 40 & 41 \\
$1-1.9$ & $39 *$ & 65 & 104 \\
$2-2.9$ & $85 *$ & 33 & 118 \\
$3-3.9$ & $29 *$ & 3 & 32 \\
$>4$ & 25 & 5 & 30 \\
\hline
\end{tabular}

* Chi-square significant correlation $(\mathrm{p}<0.01)$

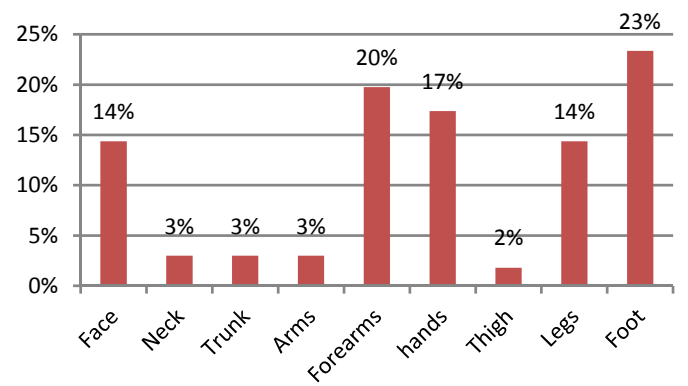

Fig. 2. Distribution of the CL lesion on anatomical sites in the study sample

lesions or distracting lesions on the face received systemic sodium stibogluconate intramuscular injection every day up to 20 days (9). After starting antileishmania treatment, the time needed for remission of CL ranged from 1.5 to 4.8 months, with the mean of $2.8 \pm 0.3$. The duration range of CL lesions from time of onset to remission was 1.3 to 14.3 months, with the mean of 5.1 \pm 0.6 . 


\section{Discussion}

Erbil Governorate in Kurdistan, Iraq, became an endemic area after 2014 with the start of military conflicts at the west fronts of this governorate. The area was evacuated after urbanization of this area. Sand-fly presence along the west borders of the governorate and presence of the army increased the incidence of CL outbreak (9).

The outbreak of CL was an emerging problem for health authorities, especially for dermatologists in this city. Approximate incidence of CL for the years 2014, 2015, and 2016 was 88, 228, 259 cases, respectively (9). As expected, the majority of the exposed individuals were from army forces $(40.3 \%)$, followed by civil residents of subdistricts of Makhmur and Gwer, near the west borders of the governorate $(25 \%)$.

Because of lack of facilities, the species have not yet been detected in this area. The claimed species of CL in Iraq are L tropica and L major (10). The pattern of clinical manifestation and course of CL in our patients in this area was not consistent with what has been mentioned in the literature about CL in Iraq. CL lesion ulceration was mostly related to the size of the lesion; lesions $2 \mathrm{~cm}$ or more in diameter got ulcerated. This finding contradicts with previously published articles, which indicated that multiple lesions usually are small and dry and not ulcerated $(2,5)$.

The time span of lesion improvement from the onset of treatment was 1.5 to 4.8 months, with the mean of $2.8 \pm 0.3$. This result is not consistent with the literature and published data from other parts of Iraq that indicated CL improves in response to standard treatment within 6 weeks (11). Another group of authors from Iraq demonstrated that after the initiation of antileishmania treatment, CL lesion heals within 4 weeks in the majority of patients (12).

A significant correlation was found between lesion ulceration and size of the lesion. Number of lesion in patients was not a predicting factor for the lesion ulceration.

Differences in the clinical presentation of CL in cases of Erbil Governorate outbreak suggest that there might be some other species of leishmaniasis or a mutation in already known species of CL in Iraq. Lack of resources to identify Leishmania species in all clinical settings of Iraq is a major barrier in identifying the species and correlating various clinical courses and responses to treatment. Thus, further studies should be done on this subject.

\section{Conclusion}

Cutaneous leishmaniasis outbreak in Erbil is different in its manifestations, course of disease, and response to standard therapy, if compared to other parts of Iraq. This warns about appearance of new species or mutations in already available species.

\section{Conflict of Interests}

The authors declare that they have no competing interests.
2. Wolff K, Goldsmith LA, Katz SI, Gilchrest BA, Paller AS. Fitzpatrick's Dermatology in General Medicine, 8th edition. McGraw Hill. 2008:2001-10.

3. Akhoundi M, Kuhls K, Cannet A. A Historical Overview of the Classification, Evolution, and Dispersion of Leishmania Parasites and Sandflies. PLOS Negl Trop Dis. 2016; 10(3):e0004349.

4. WHO. Control of the leishmaniases. World Health Organ Tech Rep Ser. 2010;(949):xii-xiii, 1-186.

5. Bolognia JL, Joseph L. Jorizzo, Julie VS. Dermatology. Third edition.Elsevier. 2012: 1360-1378.

6. Godwin KN, Mosore MT, Christopher D. First isolation of a new species of Leishmania responsible for human cutaneous leishmaniasis in Ghana and classification in the Leishmania enriettii complex. Int J Parasitol. 2015; 11:679-684.

7. Afif BS, Nathalie BM, Evelyn G. Topical Paromomycin for Cutaneous Leishmaniasis. N Engl J Med. 2013;6:524-532.

8. Sundar S, Chakravarty J. An Update on Pharmacotherapy for Leishmaniasis. Expert Opin Pharmacother. 2015;2:237-252.

9. Abdulla Q B. Factors associated with the outbreak of cutaneous leishmaniasis in Erbil governorate in 2015. KBMS dissertation. Kurdistan board for medical specialties. Iraq; 2017.

10. Al-Aubaidi IK, Mhaisen FT, Al-Bashir NM. Isolation and characterization of Iraqi leishmanial isolate. Journal of Kerbala University. 2012;1:68-77.

11. Sharquie KE., Noaimi AA, Al -Salam WS. Treatment of acute cutaneous Leishmaniasis by oral zinc sulfate and oral ketocanazole singly and in combination. J cosm dermatol sci appl. 2016; 6:105-115.

12. Sharquie KE, Noaimi AA, Al-Ghazzi AG. Treatment of cutaneous leishmaniasis by topical $25 \%$ podophyllin solution (single, blinded, therapeutic, controlled study). J Dermatol Dermatol Surg. 2015;19:108-113.

\section{References}

1. Alsamarai AM, Alobaidi HS. Cutaneous Leishmaniasis in Iraq. J Infect Dev Ctries. 2009;3:123-129. 